\title{
A RUBBER SLAT SYSTEM FOR TIED DAIRY COWS: ANIMAL CLEANLINESS, FOOT HEALTH AND BEHAVIOUR
}

\author{
Jan Hultgren ${ }^{1}$, Christer Bergsten ${ }^{2}$ \\ ${ }^{1}$ Department of Animal Environment and Health, Swedish University of Agricultural Sciences, \\ Skara, Sweden, ${ }^{2}$ Swedish Dairy Association, Skara, Sweden
}

\begin{abstract}
Although cubicle systems are increasing in Swedish dairies, still approximately $80 \%$ of the cows are kept in tie-stalls when housed. Tie-stalls are either long-stalls $(2.20 \mathrm{~m})$ or short-stalls $(1.70 \mathrm{~m})$. In long-stalls the cows are normally closed out from the feeding table when the herdsman is not in the barn, while in short-stalls they have always access to the feeding table. With less time spent per animal, higher production and larger volumes of manure, cleanliness and related foot lesions are major problems in tie-stalls. Electric cow-trainers and concrete slatted floors are banned by the animal welfare regulations and new systems are needed to improve stall hygiene. A new rubber slat system for tied dairy cows, with the ability to drain faeces and urine, was compared with a solid flooring in a two-year controlled trial in a Swedish experimental herd. Effects on animal cleanliness, foot health and behaviour were of special concern. Swedish Red and White cows were kept tied in 42 traditional long-stalls with rubber mats. In 21 stalls, the rearmost $0.74 \mathrm{~m}$ of the solid stall floor had been replaced with nine rubber-coated $53 \mathrm{~mm}$ wide slats, divided by $29-\mathrm{mm}$ slots. Cleanliness was assessed weekly (year 1) or bi-weekly (year 2) by observations of the hind part of the body. Claw measurements and foot health in hind feet were assessed in connection with claw trimmings at the beginning, middle and end of the housing period. Behaviour was studied during 48 hours in 12 matched cowpairs using video technique. The risk of getting dirty on the rubber slatted floor was significantly lower (odds ratio 0.12 for hind feet when short stall dividers were used, 0.39 for hind legs and 0.38 for thighs and udder), as compared with the solid stall floor. The prevalence of foot diseases in hind feet at trimming was significantly lower on the rubber slats (odds ratio 0.23 for dermatitis, 0.09 for heel horn erosion, and 0.34 for sole lesions). No adverse effects on animal behaviour (rising and lying down), and health (udder health, trauma) were observed. Based on the present study, the rubber slat system has been approved by the Swedish Board of Agriculture.
\end{abstract}

